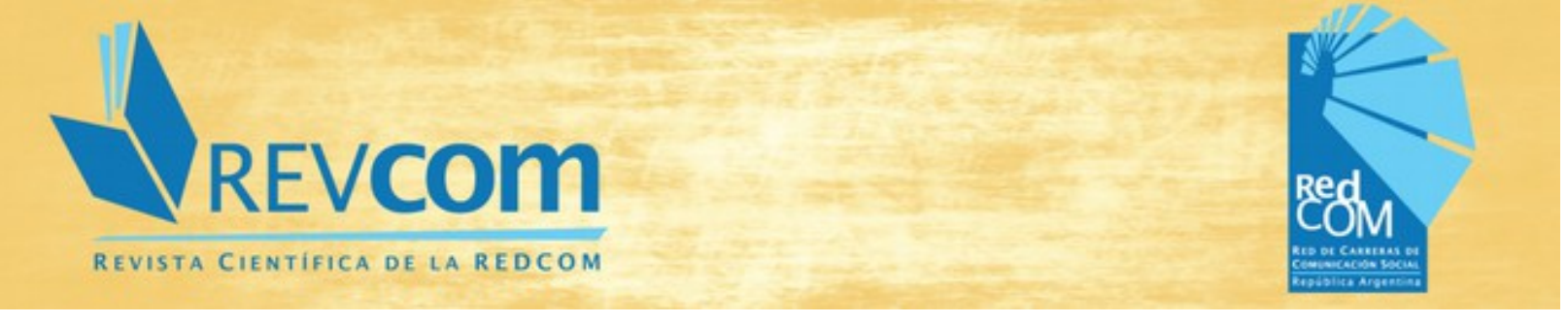

REVCOM | ISSN 2451-7836 | Año 4, \#8 | mayo de 2019 | Contribuciones | e010

\title{
Venezuela: medios comunitarios, movimientos sociales y Estado
}

\author{
Julia Porto \\ Universidad Nacional de La Plata \\ juliajuliaporto@hotmail.com
}

\begin{abstract}
Resumen:
Este trabajo recorre los vínculos entre medios comunitarios, movimientos sociales y políticas impulsadas por el Estado/los gobiernos en Venezuela, observando sus complejidades, en un intento de comprender los lugares a partir de los cuales los gobiernos progresistas y sus propuestas de fortalecimiento del aparato estatal condujeron a los pueblos en nuestra región, y particularmente, si en efecto maduraron en ese país espacios políticos basados en una construcción popular autónoma. Al mismo tiempo que el desarrollo del proceso bolivariano y de los medios de comunicación populares se relacionaron en condición de necesariedad, en el sector de medios alternativos se han construido prácticas políticas independientes, en cuyo ejercicio se concibe a sí mismo por fuera de un partido político y un Estado burocratizados, constituyendo un escenario para la visibilización de las demandas y las luchas populares.
\end{abstract}

Palabras clave: Venezuela - medios comunitarios - movimientos sociales - Estado

\section{Resumo}

Este trabalho articula os vínculos entre os meios comunitários, movimentos sociais e políticas impulsionadas pelo Estado/pelos governos da Venezuela, observando suas complexidades, com o intuito de compreender os lugares onde os governos progressistas e suas propostas de fortalecimento do aparelho estatal conduziram a população da nossa região, e particularmente, amadureceram neste país espaços políticos de construção popular autônoma. Ao mesmo tempo em que o desenvolvimento do processo bolivariano e dos meios de comunicação populares se relacionaram em condição de necessidade no setor de meios alternativos, construindo práticas políticas independentes, cujo exercício concebe a si mesmo por fora de um partido político e de um Estado burocratizados, constituindo um cenário para a visibilização das demandas e das lutas populares.

Palavras chaves: Venezuela, meios comunitários, movimentos sociais, Estado 


\section{$\downarrow_{\text {REVCOm }}$ \\ REVISTA CIENTIFICA DE LA REDCOM}

REVCOM | ISSN 2451-7836 | Año 4, \#8 | mayo de 2019 | Contribuciones | e010

Los medios comunitarios, alternativos y populares se han fortalecido y han crecido en número en Venezuela, con más fuerza desde las inmediaciones del año 2000 en adelante, constituyéndose en una alternativa comunicacional a los medios privados y a los públicos estatales. Son más de 1200 medios, en formatos digitales, audiovisuales, radiofónicos e impresos, nucleados en seis organizaciones nacionales de comunicación comunitaria audiovisual/radiofónica y más de treinta estadales (Plan Nacional de la Comunicación Popular, 2015), junto a dos coordinadoras nacionales de medios gráficos ${ }^{1}$. Algunas de estas organizaciones surgieron como estructuras asamblearias en apoyo al gobierno de Hugo Chávez, en momentos de mayor o menor conflictividad social, asumiéndose parte del proyecto bolivariano y actoras estratégicas en la construcción del "Socialismo del siglo XXI".

Este trabajo se propone ahondar en ese proceso de crecimiento y fortalecimiento, con la finalidad de describir las relaciones entre Estado, movimientos sociales y medios comunitarios en Venezuela. Surgen ante esto las siguientes preguntas: ¿Mediante cuáles modos y complejidades se han ido vinculando los movimientos sociales, los medios comunitarios y el Estado? ¿Se han construido, desde los inicios del proceso bolivariano, espacios para proyectos sociales con perspectiva de clase y para la autonomía de lo popular? ¿Algo de lo que se escenifica en los medios comunitarios es propio de sus luchas?

Cabe señalar que las discusiones presentes en el campo de la comunicación en torno a lo comunitario, lo alternativo y lo popular, no serán abordadas aquí, ya que se pretende observar en general al sector de medios que se distingue tanto del privado como del estatal, y sus vinculaciones señaladas arriba; de manera que estas expresiones se alternan a lo largo del texto.

De este modo, se ha llevado a cabo un relevamiento y un análisis teórico, siguiendo a diferentes autoras/es, y sistematizando las principales líneas conceptuales acerca del rol y el trabajo de los medios comunitarios en el contexto del proceso bolivariano. Se trata de una investigación de carácter cualitativo, que realiza un análisis interpretativo en base a

1 Las seis organizaciones nacionales de medios radiofónicos y audiovisuales: la Asociación Nacional de Medios Comunitarios, Libres y Alternativos (ANMCLA), la Asociación Civil Colectiva de Comunicadores Populares (Amebloq), el Movimiento Nacional de Televisoras Comunitarias, el Movimiento Robinsoniano de la Comunicación Popular (MoRomCoPo), el Consejo Nacional de Planificación y Participación de la Comunicación Popular y el Movimiento Social de los Medios Alternativos y Comunitarios (MoMAC). Las dos organizaciones nacionales de medios gráficos: el Bloque Venezolano de Prensa Alternativa (BVPA), el Bloque Bolivariano de Prensa Comunitaria y Alternativa (BBPCA). 


\section{REVCOm \\ REVISTA CIENTIFICA DE LA REDCOM}

REVCOM | ISSN 2451-7836 | Año 4, \#8 | mayo de 2019 | Contribuciones | e010

conceptualizaciones y experiencias, y que incluye un análisis documental, de comunicados del sector de medios comunitarios, legislación específica y noticias.

En relación con lo anterior, se analizan las estrategias y políticas impulsadas por el Estado, en vinculación con los movimientos sociales y hacia el sector de medios comunitarios; se intenta caracterizar a los movimientos sociales, describiendo los modos en que se han incorporado en las instituciones del Estado durante el proceso bolivariano, y su relación con el desarrollo de los medios comunitarios. Al mismo tiempo, se realiza una historización del crecimiento de este sector, y se atiende a sus posicionamientos políticos hacia los gobiernos bolivarianos, caracterizando brevemente por último la construcción de las agendas de los portales Aporrea y Question Digital.

\section{Dos ideas que conviven en tensión}

Observando ese período de crecimiento y fortalecimiento de los medios alternativos y comunitarios en Venezuela, se dibujan dos afirmaciones, que expresan la complejidad del mismo chavismo como fenómeno político-social.

1. Una de estas ideas es que el desarrollo del proceso bolivariano y de los medios de comunicación populares se relacionan mutua y necesariamente. Al mismo tiempo que el gobierno del presidente Chávez asumió la promoción y el desarrollo de los medios comunitarios (Pérez, 2013, p. 3), este sector concibe la comunicación del poder popular como garante de la transformación político-social bolivariana (que impulsa y apoya).

Esta toma de posición puede encontrarse, por ejemplo, en el Manifiesto del Movimiento de la Comunicación Alternativa y Comunitaria, del año 2015, firmado por las organizaciones nacionales MoRomCoPo, Amebloq y MoMAC, y por organizaciones de trece estados de Venezuela (medios y colectivos de radios, de televisoras y de periódicos y web, consejos comunales, cooperativas y otras). Así, el comunicado afirma que:

"...el movimiento de la comunicación popular, expresado en los medios alternativos y comunitarios, forma parte del amplio y variado poder popular que se enrumba a la construcción del estado comunal y por esta transformación profunda sumamos nuestra militancia y trabajo comunicacional. (...) Desde el movimiento social de la comunicación alternativa y comunitaria, como parte fundamental del poder popular organizado, enarbolamos las banderas de la Revolución Bolivariana, Chavista, Antiimperialista, Socialista y apostamos nuestras voluntades hacia la Construcción del Estado Comunal, 


\section{$\checkmark$ REVCOm \\ REVISTA CIENTIFICA DE LA REDCOM}

REVCOM | ISSN 2451-7836 | Año 4, \#8 | mayo de 2019 | Contribuciones | e010

dispuestos siempre a la batalla llena de amor patrio contra quienes desde cualquier parte pretendan imponerse contra nuestro pueblo".

2. La otra de estas ideas es que el sector de los medios alternativos y comunitarios se ha construido en una práctica política autónoma, en cuyo ejercicio las organizaciones conciben al movimiento de forma independiente de un partido político y un Estado burocratizados, sosteniendo críticas y reivindicaciones propias e imponiendo su agenda política en la conquista de derechos para la consolidación de la comunicación popular. Así, en el Manifiesto citado arriba también se afirma que las mujeres y los hombres de la comunicación popular han constituido:

"...un movimiento natural del poder popular que surge desde las bases, que no es gubernamental, pero que tampoco es privado, que está abierto a la participación y al protagonismo de todos los sectores del pueblo, porque de ahí proviene hace mucho tiempo, antes que los partidos políticos, las instituciones, los funcionarios de turno y las apetencias particulares de los tecnócratas que le hacen un flaco servicio a la Revolución Bolivariana. (...) Ni gubernamentales, ni privados, el movimiento social de la comunicación popular y los medios comunitarios y alternativos son expresión del poder popular".

Los medios comunitarios son expresión de los movimientos sociales que se encauzaron y se reconfiguraron en el proceso chavista. Su proceso de consolidación combina el carácter estratégico de la comunicación y de los medios populares en el proyecto bolivariano, con las exigencias políticas de los colectivos de la comunicación popular.

\section{Los progresismos y los pantanos}

Preguntarse por las vinculaciones entre medios comunitarios, organizaciones sociales y Estado en Venezuela, tiene que ver con incertidumbres e incógnitas mayores sobre los rumbos de los pueblos en América Latina, y los lugares (pantanosos, anegados) a los que los condujeron los progresismos. Estos gobiernos tuvieron en común la (re)articulación entre la matriz populista y el neoextractivismo desarrollista (Svampa, 2017, p. 74). Llegaron al poder a fines de la década de los noventa y principios del dos mil, después de procesos de insurgencia como los parlamentos indígenas-populares del año 2000 en Ecuador, los cuarteles aymaras en el altiplano boliviano en 2000 y 2001 y las asambleas populares de Argentina en 2001 y 2002 (Machado y Zibechi, 2016, p. 25). Las propuestas electoralistas y de fortalecimiento del aparato 
REVCOM | ISSN 2451-7836 | Año 4, \#8 | mayo de 2019 | Contribuciones | e010

estatal supieron procesar y encauzar la mayoría de los reclamos sociales ${ }^{2}$, institucionalizando las luchas de 'las' y 'los de abajo' en los marcos del Estado. Los progresismos combatieron la pobreza mediante planes asistenciales, financiando sus políticas sociales con los precios altos de los commodities, como la soja, el petróleo y los minerales. La expansión continua de la frontera extractiva y la apertura de los territorios a los capitales transnacionales, estuvieron unidas a la vulneración de derechos ambientales y sociales, perpetuando un modelo económico que no necesita trabajadoras/es para sostenerse. Sus gobiernos no llevaron adelante reformas estructurales y se agotaron, a la vez que se produjo de forma compleja el viraje hacia la derecha de la región.

$\mathrm{Si}$, como dicen Decio Machado y Raúl Zibechi, parece evidente "que la cultura política o, quizá mejor, el sentido común en las izquierdas y en los movimientos, no puede pensar en un nuevo mundo que no se referencie en el Estado, el gobierno y los partidos políticos" (2016, p. 27), también se hace evidente que el hecho de sostener lazos con los capitales transnacionales extractivos, es incompatible con un deseo verdadero de planificar y poner en práctica modelos sustentables, que busquen la soberanía alimentaria, que se desplacen de la explotación de la naturaleza como lógica (Fernández Guerrero, 2010) y superen la separación ser humano/naturaleza.

\section{La democratización del Estado venezolano \\ y el nuevo cauce de los movimientos de abajo}

En esta mirada, Venezuela aparece como un caso paradigmático: la revuelta popular conocida como "el Caracazo" en 1989 tuvo carácter de insurrección armada, y generó un quiebre en el sistema político bipartidista (Alaniz, 2015, p. 19), que se había sostenido desde 1958, con un acuerdo de gobernabilidad entre los partidos Acción Democrática y COPEI, conocido como Pacto de Punto Fijo. Así, mientras se mantuvo el bipartidismo, "muchas de las iniciativas populares eran canalizadas a través de AD y COPEI (...). Las organizaciones sociales eran inexistentes o apéndices de aquellos. Eran domesticadas por vía del consenso o reprimidas, si fuera el caso" (Villalobos Finol, s.f, p. 42). El Caracazo abrió "un vacío que fue ocupado, muy pronto por cierto, por el chavismo como fenómeno popular, mucho antes de que se convirtiera en gobierno" (Machado y Zibechi, 2016, p. 8); después, en los años siguientes y a lo largo de la década de los '90, iría surgiendo "el pueblo-masa-nación como nuevo sujeto político" (Denis, 2011; citado en Machado y Zibechi, 2016): en las periferias urbanas creció la 2 Con excepción del levantamiento indígena zapatista de 1994 (Machado y Zibechi, 2016, p. 25). 


\section{$\searrow_{\text {REVCOM }}$ \\ REVISTA CIENTIFICA DE LA REDCOM}

REVCOM | ISSN 2451-7836 | Año 4, \#8 | mayo de 2019 | Contribuciones | e010

movilización de estudiantes y de pobladores de barrios populares, se multiplicaron redes culturales y de educación popular, cooperativas, medios de comunicación comunitarios. El proceso generaría una serie de cambios políticos y culturales, que serían encauzados bajo el liderazgo político de Hugo Chávez y su propuesta de construcción del "Socialismo del Siglo XXI".

La reforma de la Constitución de 1999 impulsó la construcción de instancias de democracia directa dentro de los marcos del Estado. Además, una serie de normas impulsaron el fortalecimiento de las organizaciones sociales, entre las que pueden nombrarse la Ley de los Consejos Comunales (2006) y la posterior Ley Orgánica de las Comunas (2010). La primera buscaba la creación de espacios que permitieran "al pueblo organizado ejercer directamente la gestión de las políticas públicas y proyectos orientados a responder a las necesidades y aspiraciones de las comunidades" (Ley de los Consejos Comunales, 2006); la segunda fue propuesta por Hugo Chávez como el camino "para la edificación del estado comunal, en el marco del Estado democrático y social de derecho y de justicia" (Ley Orgánica de las Comunas, 2010), definiendo a las comunas como espacios autoorganizados, "donde los ciudadanos y ciudadanas en el ejercicio del Poder Popular, ejercen el pleno derecho de la soberanía y desarrollan la participación protagónica mediante formas de autogobierno" (Teruggi, 2015)

De forma sencilla, Machado y Zibechi afirman que "a diferencia de los soviets en Rusia, las comunas han sido creaciones desde arriba, lo que significa que están sometidas a ese arriba que las creó" (2016: 17). Afirman que las comunas son "organismos locales que sustentan el poder popular pero que, en realidad no tienen poder, debido a que no cuentan con un aparato de coerción capaz de hacer realidad las decisiones que toman" (2016, p. 13); "todas las instancias del 'poder popular' venezolano están sometidas a la Constitución, al poder público y a las leyes existentes como surge nítidamente de la Ley de Comunas, donde las formas de autogobierno funcionan 'en el marco del Estado democrático', según su artículo $1^{\circ}$. No es, por lo tanto, un contrapoder, sino un engranaje más de los poderes existentes" (2016, p. 13).

\section{Los medios configurándose en las comunidades: una breve historización}

Puede pensarse a los medios comunitarios como espacios abiertos a la participación, permeables a los conflictos, las reivindicaciones y la celebración de las comunidades en las 


\section{REVCom \\ REVISTA CIENTIFICA DE LA REDCOM}

REVCOM | ISSN 2451-7836 | Año 4, \#8 | mayo de 2019 | Contribuciones | e010

que se insertan (Villalobos Finol, 2012). Así, es posible interpretar que los procesos de las comunidades se ven expresados en las transformaciones de los medios que se gestan en ellas; comunidades y medios van juntos, los medios creciendo a la par de los cambios sociales.

Un antecedente inicial tiene origen en los movimientos sociales y políticos de los años '70 y '80: los primeros proyectos comunitarios eran periódicos impresos, ligados a movimientos cristianos de base y a partidos de izquierda, en los que circulaban demandas sociales y se difundían propuestas políticas (Villalobos Finol, 2012, p. 40); también, se realizaban murales vecinales, cine foros y radios comunitarias, entre otras prácticas.

Durante los años '90 emergieron con fuerza las radios comunitarias: Radio Morrocoy, la primera en Caracas y convertida después en Radio Catia Libre 93.5 FM, comenzó su trabajo en 1996; la seguirían desde 1998 Radio Alternativa, Radio Perola y Radio Activa de La Vega (Anmcla, 2008 b). También en esa década se desarrollaron algunas experiencias de comunicación y organización vecinal, como la Escuela de Vecinos, la Agencia Buenas Noticias, el Centro al Servicio de la Acción Popular-CESAP, el Movimiento de Integración de la Comunidad-MIC, centradas en la participación ciudadana y el uso alternativo de los medios (Pérez, 2013, p. 2).

Con la reforma de la Constitución se produjeron transformaciones a nivel social que también se expresarían en el campo de los medios alternativos (Villalobos Finol, 2012, p. 43): proliferaron un conjunto de organizaciones populares generándose, al mismo tiempo, un crecimiento general de la participación política de la sociedad, que se materializó en tendencias nuevas en la comunicación. Así, se pasó a concebirla como una actividad social de interés público, atendiendo a la importancia de los medios como formadores de sujetos y constructores de ciudadanía, buscando generar cambios en la administración del espectro radioeléctrico y democratizar el acceso y el uso de las tecnologías de la información. Además de medios comunitarios, en ese proceso surgieron espacios como consejos comunales y cooperativas, comités de usuarios de diferentes servicios públicos, sindicatos, fundaciones, y una gran cantidad de organizaciones ${ }^{3}$; este panorama aparece en un arqueo mediático realizado a la prensa venezolana (Villalobos y Rosillón, 2010, en Villalobos Finol, 2012).

A partir del año 2000, los medios comunitarios se fortalecieron y crecieron en número, en un proceso que combinó la lucha política del sector y el reconocimiento por parte del gobierno

3 Asociaciones de vecinos, asociaciones civiles, frentes, bloques, contralorías sociales, alianzas, juntas administrativas, redes, ONGs, activistas, organizaciones directivas, sociedades, colegios, productores, de jóvenes y estudiantes, de docentes, entre otras (Villalobos Finol, 2012). 
REVCOM | ISSN 2451-7836 | Año 4, \#8 | mayo de 2019 | Contribuciones | e010

de la comunicación popular como estratégica para su proyecto. En esa dinámica, el gobierno de Hugo Chávez impulsó la creación de marcos institucionales y legales y de proyectos específicos, que se profundizaría con la "redimensión del rol" de los medios alternativos a partir del golpe de Estado del 2002 (Mujica, s. f). Luego, en el gobierno de Nicolás Maduro se obtuvieron logros importantes para el sector, como la aprobación de la Ley de Comunicación del Poder Popular (2015).

\section{La puja por una regulación jurídica específica}

Las reformas en la Constitución exigieron que se adaptara el ordenamiento jurídico vigente a los marcos de una democracia participativa: esos cambios fueron generados con la disposición política del gobierno, junto a las presiones políticas y sociales de los movimientos populares, buscando plasmar en lo legal las reivindicaciones de sus luchas. En esta trama, se inscribe el marco jurídico de referencia a los medios comunitarios, gestado en esa puja posible por la voluntad del chavismo y las organizaciones que señalaron el camino: "No habrá verdadera democracia ni acceso a la información, si no se extiende la libertad de crear medios a las comunidades organizadas, en condiciones de igualdad y con un marco legal que favorezca el desarrollo de los mismos" (Manifiesto por la Librecomunicación, 2000. Declaraciones, punto 2).

Distintos grupos, articulados en un nivel nacional en el Movimiento por la Librecomunicación, exigieron el reconocimiento oficial del sector de medios comunitarios como un componente esencial de la radiodifusión de servicio público y como contribución vital al pluralismo. Plantearon la creación por parte del Estado de un espacio público para el debate, en el que las comunidades organizadas participaran en el diseño e instrumentación de las políticas y normativas en comunicaciones; reclamaron que el Estado destinara ingresos fiscales para planes de desarrollo y de formación de la comunicación comunitaria, provenientes de las contribuciones de empresas de telecomunicaciones.

Es necesario señalar que otras organizaciones realizaron lecturas distintas del proceso, como el ejemplo de Amebloq (Heredia, 2012), que afirma haber contado con el apoyo personal del presidente Chávez a poco de su conformación como bloque bolivariano de periodistas en 1998, generando posteriormente una "alianza estratégica" con el gobierno, e incorporándose al Gran Polo Patriótico en el 2011. 
REVCOM | ISSN 2451-7836 | Año 4, \#8 | mayo de 2019 | Contribuciones | e010

En el Manifiesto por la Librecomunicación (2000) puede verse parte del diagnóstico en base al que el Movimiento por la Librecomunicación planteó sus exigencias:

"PREOCUPADOS por las amenazas para la vigencia del derecho a la libre comunicación que pueden derivarse del diseño del marco legislativo de las telecomunicaciones, a causa del protagonismo de las grandes corporaciones y la exclusión de la participación de colectivos populares, la comunidad organizada y otros sectores de la sociedad; y CONSIDERANDO que los nuevos poyectos de Ley y Reglamento de Telecomunicaciones que se discuten son acuerdos negociados entre el Estado y la empresa privada, que conciben las telecomunicaciones como actividades exclusivamente económicas y han sido diseñados especialmente para aprovechar la oportunidad fiscal que ofrece la apertura del sector de las telecomunicaciones a partir del año 2000".

La aprobación de la Ley Orgánica de Telecomunicaciones (Lotel) el 12 de junio del 2000, se dio en continuidad con la reivindicación en la Constitución de la comunicación como un derecho humano, de la libertad de expresión y del libre acceso a la información (arts 57, 58, 101, 108). Así, en la Lotel se incorporaron algunos artículos de referencia a la comunicación comunitaria, con el impulso del Movimiento por la Librecomunicación. (Anmcla, 2008 a). El artículo 2 de esta ley estableció como deber del Estado "promover y coadyuvar al establecimiento de medios de radiodifusión sonora y televisión abierta comunitarias de servicio público sin fines de lucro, para el ejercicio del derecho a la comunicación libre y plural" (Lotel, 2000); además, definió los mecanismos para la tramitación de las licencias.

Sobre la redistribución del espectro radioeléctrico, María Cruz Tornay (2014) dice que la reforma supuso un avance en ese momento, pero que "lejos del reparto porcentual y equitativo aprobado en países como Ecuador, Argentina o Bolivia, la Ley de Telecomunicaciones cede a la radiodifusión comunitaria los espacios huecos que deja la privada y hoy la distribución del espectro se reparte aproximadamente entre un 80 por ciento para los medios privados, un 18 para públicos y un escaso 2 por ciento para los comunitarios" (Tornay, 2014).

A partir de la aprobación de la Lotel comenzó un proceso de crecimiento de radios y televisoras comunitarias: en el 2001 se fundaron Catia TV, el primer canal de televisión habilitado, y las radios Alí Primera, Macarao y Senderos de Antímano (Pérez, 2013).

Quedaba pendiente responder a la necesidad de una regulación específica para el sector: el Reglamento de Radiodifusión Sonora y Televisión Abierta Comunitaria fue redactado en 
REVCOM | ISSN 2451-7836 | Año 4, \#8 | mayo de 2019 | Contribuciones | e010

coordinación entre las organizaciones y Conatel, y finalmente aprobado el 8 de enero del 2002. Desde Anmcla, describen el proceso en el que se gestó: "Dos encuentros por la Librecomunicación, varios más como consulta del reglamento, la disposición política del gobierno nacional, acciones legales y de calle generaron el Reglamento de Radiodifusión" (Marco legal de la Comunicación Comunitaria, 2008). Entre otras disposiciones, estableció que los medios debían ser fundaciones democráticas, arraigadas y con un proyecto integral comunitario, y determinó la necesidad de que emitieran desde un $70 \%$ de producción comunitaria. Este reglamento fijó los objetivos de garantizar la comunicación libre y plural de las comunidades organizadas y servir de base para el desarrollo del sector de radio y televisión comunitarias.

\section{Los medios comunitarios se redimensionan: el golpe y después}

El 11, 12 y 13 de abril del 2002, el golpe de Estado a Hugo Chávez terminó de revelar la importancia estratégica del sector de medios comunitarios para el proyecto bolivariano. Las cadenas privadas Globovisión, Venevisión, RCTV y Televen, realizaron campañas de destitución y desinformación, como parte del golpe planificado y llevado adelante junto a la Federación de Empresarios Fedecámaras, la Confederación de Trabajadores de Venezuela y las cúpulas de PDVSA. El canal público Venezolana de Televisión había sido sacado del aire; los medios comunitarios realizaron una tarea fundamental, denunciando el ataque a la legalidad democrática y visibilizando el respaldo popular a Chávez ${ }^{4}$ (Tornay, 2014). La mayoría de las emisoras que cubrieron el estallido social "eran radios que venían de la clandestinidad y represión en los años de presidencia de Rafael Caldera y que dejaron de ser perseguidas a partir de 1998" (Tornay, 2014). ${ }^{5}$

Con la recuperación de la democracia, el gobierno impulsó la creación del Ministerio del Poder Popular para la Comunicación y la Información (MinCl), y puso en marcha planes de

4 Ver: Documental "Venezuela bolivariana: Pueblo y lucha de la IV guerra mundial". Realizado por el Colectivo Calle y Media.

5 En esa coyuntura, la Asamblea Popular Revolucionaria fue un espacio de coordinación que se organizó "para enfrentar la ofensiva golpista de la burguesía venezolana contra el gobierno del Presidente Hugo Chávez y para la defensa de las conquistas de la Constitución de la República Bolivariana" (en aporrea.org/nosotros), a partir de la que surgieron medios de comunicación como el portal de noticias Aporrea; también, tiempo después, habrá periodistas que se retiren de sus colectivos de comunicación para incorporarse a cargos públicos, como la co-fundadora de Catia TV Blanca Eeckhout, ministra de Comunicación e Información (2009/2010), o Martín Sánchez, cofundador de Aporrea, que en 2004 asumió un cargo diplomático del gobierno venezolano. 


\section{$\searrow_{\text {REVCOM }}$ \\ REVISTA CIENTIFICA DE LA REDCOM}

REVCOM | ISSN 2451-7836 | Año 4, \#8 | mayo de 2019 | Contribuciones | e010

financiamiento, capacitación y entrega de equipos en comodato a medios alternativos y comunitarios.

Organizaciones como Anmcla verán al proceso como "una posibilidad cada vez más cercana de librar una dura batalla por la democratización del espacio radioeléctrico nacional", ante "el ataque continuo por parte de los grandes medios comerciales" (Anmcla, 2004).

Según datos de Conatel, entre el 2002 y el 2006 se habilitaron 193 nuevos medios radioeléctricos; para el 2011 había 244 radios y 36 emisoras de televisión habilitadas; en un operativo iniciado en 2017 y continuado en 2018, se esperaba regularizar 200 medios comunitarios en todo el país; algunos medios señalaron el proceso de adquisición de licencias como "engorroso" (Pérez, 2013).

La Ley de Responsabilidad de Radio y Televisión (Ley Resorte 2010, Ley Resorteme a partir de las reformas del 2014), estableció una serie de disposiciones relacionadas a la responsabilidad sobre la producción de contenidos y los derechos de quienes consumen los medios, y hace referencia en particular a los servicios de radio y televisión comunitarios de servicio público sin fines de lucro en su artículo 16.

En el 2011, colectivos de la comunicación popular presentaron el proyecto de la Ley de Comunicación del Poder Popular, elaborado por voceras y voceros de las organizaciones. En la ley, discutida y aprobada en 2015 en la Asamblea Nacional, es central la idea de que la comunicación popular es aquella que ejerce el pueblo en la gestión de sus propios medios, distintos de los privados, pero también de los públicos. El "Pueblo Comunicador" garantiza en su ejercicio el derecho fundamental a la información y a la comunicación. Con los objetivos de impulsar, desarrollar, fortalecer y consolidar la Comunicación Popular (art. 2), la ley les otorga respaldo jurídico a las instancias organizativas surgidas en el propio proceso de crecimiento de los medios populares en Venezuela: un Consejo Nacional, Consejos Estadales y Consejos Municipales incorporados por esta ley.

La ley propone continuar la democratización del espectro radioeléctrico y plantea mecanismos de financiamiento, capacitación, seguridad social para las comunicadoras y los comunicadores, entre otros aspectos (Gómez, 2016). La derecha presentó sus resistencias, sosteniendo que "debía promoverse un trato justo y equitativo a todos los tipos de medios de comunicación, sean estos públicos, privados o comunitarios", malinformando que la ley daría "prioridad a los 'Medios de Comunicación para el Poder Popular' sobre el espectro 


\section{$\checkmark$ REVCOm \\ REVISTA CIENTIFICA DE LA REDCOM}

REVCOM | ISSN 2451-7836 | Año 4, \#8 | mayo de 2019 | Contribuciones | e010

radioeléctrico nacional", siendo una medida "contraria a los estándares de derechos humanos de libertad de expresión" (Gómez, 2016).

También en 2015 el Ministerio del Poder Popular para la Comunicación y la Información (MinCi) en el gobierno de Nicolás Maduro lanzó el Plan Nacional de la Comunicación Popular 2015-2019, que se propone la construcción y el fortalecimiento del Sistema Nacional Popular de Comunicación Popular. Este proyecto plantea metas, estrategias y acciones en formación de comunicadoras y comunicadores, producción de contenidos propios, sustentabilidad y uso responsable del espectro radioeléctrico, definidas a partir de un diagnóstico de las debilidades de los MAC en Venezuela.

\section{Algunas ideas finales}

Los vínculos entre medios comunitarios, movimientos sociales y políticas impulsadas por el Estado/los gobiernos bolivarianos presentan coincidencias, necesariedades y contradicciones. La complejidad del caso venezolano parece estar dada por la estrategia llevada adelante, en la que un movimiento de masas fue canalizado en los marcos del Estado. En el proceso se observa una doble relación: había una fuerza social, que luego fue reimpulsada desde el aparato estatal; ese movimiento social multiplicó su presencia en los territorios y dio forma a su organización, en las instituciones y los espacios de participación generados por el chavismo. Veinte años después de la llegada al poder de Hugo Chávez, el presente de Venezuela, leído en continuidad con aquello, parece demostrar que la construcción de poder popular autónomo no es viable en los marcos del Estado y de los partidos políticos, que no es hacia allí hacia donde debe guiarse una fuerza nacida de una insurrección.

Con la producción de petróleo en baja, un aparato productivo casi paralizado, la profundización del modelo extractivo como salida articulada por el gobierno, un gran desabastecimiento de alimentos y de medicinas, las políticas sociales desfinanciadas, una altísima inflación que pulveriza el salario de las mayorías y desencadena la migración hacia otros países de América Latina, Venezuela atraviesa una crisis profunda. Luego de un 2017 marcado por enfrentamientos violentos entre la oposición y el gobierno, Nicolás Maduro obtuvo nuevamente la presidencia en 2018, alcanzando el $68 \%$ en unas elecciones con baja participación, ante una oposición que aparecía fragmentada.

Sin perder de vista la dimensión de la agresión imperialista internacional, escenario en el que se suceden las sanciones simbólicas, económicas y financieras de Estados Unidos, la 
REVCOM | ISSN 2451-7836 | Año 4, \#8 | mayo de 2019 | Contribuciones | e010

Unión Europea, el Grupo de Lima y la OEA, resulta clara la mirada de Carlos Carcione, quien había señalado que la confrontación entre las cúpulas no ha sido una pelea entre los sectores populares y los oligárquicos. "Por el contrario, es una lucha por definir cuál de las cúpulas se garantiza, en el próximo período, el control del Estado, para administrar y distribuir la renta. Son dos sectores de las élites, subordinados al capital financiero internacional, uno tradicional y otro emergente" (2017). Así, afirma que las organizaciones deben posicionarse ante el contenido de las políticas del PSUV, observando qué sectores sociales expresan, qué consecuencias le generan al país y a la población.

En el desarrollo del proceso bolivariano, el sector de medios comunitarios tuvo un rol necesario, apoyándolo y colaborando en garantizarlo; fundamentalmente, a partir del golpe de Estado del año 2002, en el que se revelaría en profundidad su carácter estratégico para el proyecto, y a partir del que Hugo Chávez profundizaría el impulso al sector. Aquí encontramos nuevamente una doble relación: al mismo tiempo que hubo una acción desde el Estado para el crecimiento del sector, las organizaciones de medios comunitarios se han concebido de forma autónoma, instalando sus reivindicaciones políticas ante los gobiernos bolivarianos, y logrando de ese modo materializar sus demandas.

En este sentido, aunque hoy el gobierno y la oposición (y sus proyectos) son presentados en la mayoría de los medios como únicas fuerzas, al prestar atención a la diversidad de voces que se presentan en medios alternativos y comunitarios, pueden encontrarse posturas que se desmarcan del gobierno de Nicolás Maduro. Así, observando los medios web Aporrea y Question Digital entre marzo y diciembre del 2017, surgieron una serie de miradas y de actores sociales que construyen una visión crítica por izquierda y cuestionan el hecho de que Maduro represente los intereses populares: sectores de comunidades y sindicales, la Plataforma Ciudadana en Defensa de la Constitución, la Plataforma contra el Arco Minero del Orinoco, la Plataforma por la Auditoría Pública y Ciudadana, partidos escindidos del GPP y de orientación trotskista.

Brevemente, algunos de los puntos que estos colectivos señalan son: en el plano económico, cuestionan el pago puntual de la deuda externa, en detrimento de las importaciones; indican que el plan de impulso de los quince motores de la economía significa la profundización del modelo extractivista, con proyectos megamineros como el Arco Minero del Orinoco, y exenciones impositivas y arancelarias a empresas extranjeras. Afirman un retroceso del sistema político, con fuertes rasgos autoritarios, que se expresarían en el gobierno por 


\section{VREVCOm \\ REVISTA CIENTIFICA DE LA REDCOM}

REVCOM | ISSN 2451-7836 | Año 4, \#8 | mayo de 2019 | Contribuciones | e010

decreto de Maduro, la continuidad del estado de excepción, la fragmentación institucional dada por las disputas entre el Tribunal Supremo de Justicia y la Asamblea Nacional, y por la inconstitucionalidad de la Asamblea Constituyente, dada por una representación desigual en las bases comiciales y por su carácter plenipotenciario. En lo social, denuncian la decadencia de las políticas sociales a partir de la caída de los precios del petróleo, también el crecimiento de la violencia policial en los barrios de clases bajas. Algunas de las notas de las que se ha sistematizado esta información, son: "Periodismo incorporado: sobre los aparatos de propaganda de la OLP", publicada en Question Digital el 19 de marzo del 2017; "El hilo constitucional sigue roto. Por el restablecimiento de la Constitución", firmada por la Plataforma Ciudadana en Defensa de la Constitución, y publicada en Aporrea el 14 de abril del 2017; una entrevista realizada a Carlos Carcione, "Nos estamos moviendo entre la falsa Constituyente de Maduro, la guerra civil/aplastamiento que propone Atilio Borón o la recuperación de la vigencia de la Constitución del '99", publicada en Aporrea el 5 de junio del 2017; "Plataforma Ciudadana en Defensa de la Constitución llama a la abstención y el voto nulo a la Constituyente", publicada en Aporrea el 25 de julio del 2017; entre otras. Asimismo, varios comunicados de las organizaciones de medios comunitarios han sido tomados de estos portales.

Como se ha visto, los medios comunitarios tienen un vínculo estrecho con los procesos que atraviesan las comunidades en las que se insertan, con sus reivindicaciones y con sus luchas. Observando tanto su proceso de fortalecimiento como la construcción de sus agendas, cuyo tratamiento informativo sobre la realidad nacional de Venezuela puede situarse por fuera de la dicotomía gobierno/oposición -reproducida tanto en medios privados y estatales como en las agendas internacionales de otros países-, es posible pensar que la existencia de medios comunitarios habilita escenarios para las luchas populares, y hace visible la presencia tanto de una mirada crítica como de una alternativa política, en el espacio de lo público.

\section{BIBLIOGRAFÍA}

Alaniz, M. (2015). (Comp.). Medios informativos y gobiernos en la historia contemporánea de Sudamérica (2004-2014). Córdoba. Editorial Copi Rápido.

Anmcla, (2004). Venezuela: Medios Comunitarios, Libres y Alternativos. Recuperado de http://barcelona.indymedia.org/newswire/display/80235/index.php

Anmcla, (2008 a). Marco legal de la Comunicación Comunitaria. Recuperado de https://issuu.com/vocesurgentes/docs/marco_legal 
REVCOM | ISSN 2451-7836 | Año 4, \#8 | mayo de 2019 | Contribuciones | e010

Anmcla, (2008 b). Venezuela: Medios Comunitarios, Libres y Alternativos. Somos expresión de la multitud. Recuperado de http://vocesurgentes.codigosur.net/leer.php/3369674.html

Anmcla, (2011). Entrevista a Natalí Mendoza. Recuperado de https://www.youtube.com/watch? $v=E \_a t 18 F y 92 c$

Aporrea. Recuperado de https://www.aporrea.org/

Ávila, K. (2017). "Periodismo incorporado: sobre los aparatos de propaganda de la OLP". Question Digital [en línea]. Consultado el 20/08/2017 en <http://questiondigital.com/periodismo-incorporadosobre-los-aparatos-de-propaganda-de-la-olp/>

Carcione, C. (2017). "Nos estamos moviendo entre la falsa Constituyente de Maduro, la guerra civil/aplastamiento que propone Atilio Borón o la recuperación de la vigencia de la Constitución del “99”. Aporrea [en línea]. Consultado el 19/08/2017 en <https://www.aporrea.org/ddhh/n309525.html>

Colectivo Calle y Media, (productor). (2012). Venezuela bolivariana: Pueblo y lucha de la IV guerra mundial. Recuperado de https://www.youtube.com/watch?v=eP8VDYeBRdw\&t=3890s. Venezuela.

Conatel. Recuperado de http://www.conatel.gob.ve/

Fernández Guerrero, O. (2010). "Cuerpo, espacio y libertad en el eco feminismo". Nómadas, Revista Crítica de Ciencias Sociales y Jurídicas, (27), s/pp.

Gómez, G. (2016). "Aprobada y en gaceta la Ley de Comunicación del Poder Popular con importantes avances y conquistas". Resumen Latinoamericano [en línea]. Consultado el 11/10/2017 en $<$ http://http//www.resumenlatinoamericano.org/2016/01/03/venezuela-aprobada-y-en-gaceta-la-leyde-comunicacion-del-poder-popular-con-importantes-avances-y-conquistas/>

Heredia, L. (2012). "Felicitaciones al Bloque Bolivariano de Medios al cumplir 14 años comunicando en Revolución". MINCI [en línea]. Consultado el 03/02/2018 <http://minci.gob.ve/2012/08/felicitaciones -al-bloque-bolivariano-de-medios-al-cumplir-14-anos-comunicando-en-revolucion/>

Informe Anual sobre situación en Venezuela 2004-2005: Ejercicio de la libertad de expresión por medios de comunicación comunitario. (S.f). Recuperado de http://www.apc.org/apps/img_upload/irlacdocumentos/ALC_Informe_situacion_en_Venezuela.pdf

Ley de Comunicación del Poder Popular. Gaceta Oficial Extraordinaria N 6207, 28/12/2015. Recuperado de http://www.minci.gob.ve/wp-content/uploads/2016/07/Ley-de-la-Comunicacion-del-PoderPopular1.pdf

Ley Orgánica de las Comunas. Gaceta Oficial N6011. Recuperado de https://softwarepublico.gob.ve/documentos/pdf/ley_organica_de_las_comunas.pdf

Ley Orgánica de Telecomunicaciones. Gaceta Oficial №36.970, 12/06/2000. Recuperado de http://www.conatel.gob.ve/files/Ley_Organica_Telecomunicaciones-2000-G.0.\%2036970.pdf

Ley de Responsabilidad Social en Radio y Televisión. Gaceta Oficial №38.081, 7/12/2004. Recuperado de http://www.minpet.gob.ve/images/biblioteca/leyes/ Ley_de_reforma_parcial_de_la_Ley_ de_Responsabilidad_Social_en_Radio_y_Television.pdf 
REVCOM | ISSN 2451-7836 | Año 4, \#8 | mayo de 2019 | Contribuciones | e010

Machado, D. y Zibechi, R. (2016). Cambiar el mundo desde arriba. Los límites de los progresismos. La Paz, Bolivia: Centro de Estudios para el Desarrollo Laboral y Agrario (CEDLA).

Manifiesto del Movimiento de la Comunicación Alternativa y Comunitaria del Poder Popular, (2015). Consultado el 03/10/2017 en <http://www.resumenlatinoamericano.org/2015/02/08/venezuelamanifiesto-del-movimiento-de-la-comunicacion-alternativa-y-comunitaria-del-poder-popular/>

Manifiesto del Movimiento de la Comunicación Popular - Trujillo, (2015). Consultado el 28/09/2017, en <http://guapotori.blogspot.com.ar/2015/02/manifiesto-del-movimiento-de-la.html>

Movimiento Social de los Medios Alternativos y Comunitarios (MoMac), (2008). "Fundamentación política, conceptual y programática". Aporrea[en línea]. Consultado el 28/09/2017, en <https://www.aporrea.org/medios/a52496.html>

Mujica, P. (s/a). "Los medios comunitarios en Venezuela". INVECOM [en línea]. Consultado el 24/04/2017 en <http://www.invecom.org/eventos/2009/pdf/mujica_p.pdf>

Pérez, J. (2013). "Comunicación Alternativa en Venezuela: cambios y continuidades". Instituto de Investigaciones de la Comunicación ININCO-UCV, Caracas [en línea]. Consultado el 11/11/2017 en <https://visionesyficciones.files.wordpress.com/2013/03/ponencia-congreso-oncti-peiicomunicacic3b3n-alternativa-en-venezuela.pdf>

Plan Nacional de la Comunicación Popular (2015-2019), (2015). Ministerio del Poder Popular para la Comunicación y la Información. Consultado el 15/10/2017 en <http://minci.gob.ve/2015/10/plannacional-de-la-comunicacion-popular-2015-2019/>

Plataforma Ciudadana en Defensa de la Constitución (2017). "El hilo constitucional sigue roto. Por el restablecimiento de la Constitución". Aporrea [en línea]. Consultado el 17/04/2017 en <https://www.aporrea.org/actualidad/a244201.html>

Prensa Marea Socialista (2017). "Plataforma Ciudadana en Defensa de la Constitución llama a la Abstención y el voto nulo en la Constituyente". Aporrea [en línea]. Consultado el 27/07/2017 en $<$ https://www.aporrea.org/actualidad/n311966.html>

Question digital. Recuperado de http://www.questiondigital.com/

Reglamento de Radiodifusión Sonora y Televisión Abierta Comunitarias de Servicio Público, sin fines de lucro. Decreto $\mathrm{N}^{\circ}$ 1.521, 08/01/2002. Recuperado de http://www.conatel.gob.ve/wpcontent/uploads/2014/11/Reglamento_de_Radiodifusion.pdf

Svampa, M. (2017). Del cambio de época al fin del ciclo. Gobiernos progresistas, extractivismo y movimientos sociales en América Latina. Buenos Aires: Edhasa.

Tornay, M. C. (2014). "La comunicación en manos del poder popular". Pueblos - Revista de Información y Debate [en línea]. Consultado el 10/02/2018 en <http://www.revistapueblos.org/blog/2014/07/27/lacomunicacion-en-venezuela-en-manos-del-poder-popular/>

Teruggi, M. (2015). Lo que Chávez sembró. Testimonios desde el socialismo comunal. Lomas de Zamora: Sudestada. 
REVCOM | ISSN 2451-7836 | Año 4, \#8 | mayo de 2019 | Contribuciones | e010

Villalobos Finol, O. (2012). "Los medios comunitarios en Venezuela: presencia, conflictos y retos actuales", Revista Comunicación, [en línea] Consultado el 10/10/2017 en $<$ http://clacpi.org/observatorio/los-medios-comunitarios-en-venezuela-presencia-conflictos-y-retosactuales/>

Zibechi, R. "La crisis de los gobiernos progresistas se debe a su incapacidad para salir del modelo extractivo". Resumen Latinoamericano [en línea]. Consultado el 11/02/2018 en

$<$ http://www.resumenlatinoamericano.org/2016/05/10/entrevista-a-raul-zibechi-la-crisis-de-los-gobiernosprogresistas-se-debe-a-su-incapacidad-para-salir-del-modelo-extractivo/>

"200 medios comunitarios serán regulados a través de Conatel en todo el país" [en línea]. Consultado el 10/03/2018, en <http://www.noticiasbarquisimeto.com/2018/02/20/200-medios-comunitarios-seranregulados-a-traves-de-conatel-en-todo-el-pais/>

Artículo recibido el 27-08-2018 | Aceptado el 06-12-2018 | Publicado 26-05-2019

http://perio.unlp.edu.ar/ojs/index.php/revcom/ Esta obra está bajo una Licencia Creative Commons Atribución-NoComercial-SinDerivar 4.0 Internacional 